\title{
Certificação de fornecimento e custos de transação: resultados do programa integrado de desenvolvimento e qualificação de fornecedores - prodfor
}

\author{
André Carlos Busanelli de Aquino ${ }^{\mathrm{a} *}$, José Tarciso Meneguette ${ }^{\mathrm{b}}$, Marcelo Sanches Pagliarussi ${ }^{\mathrm{c}}$ \\ a*aaquino@usp.br, FEARP/USP, Brasil \\ bjtarciso@uol.com.br, Fucape Business School, Brasil \\ ‘marcelo@fucape.br, Fucape Business School, Brasil
}

\begin{abstract}
Resumo
0 presente estudo teve dois objetivos complementares: entender o desenvolvimento da instituição privada Programa Integrado de Desenvolvimento e Qualificação de Fornecedores (Prodfor), um programa específico de padronização e certificação de fornecedores locais de produtos e serviços no estado do Espírito Santo; e testar se o programa causou redução de custos de transação para as mantenedoras nas compras de bens e serviços. Foram utilizados os conceitos da nova economia institucional para desenvolver hipóteses a respeito do impacto da certificação sobre o desempenho de compras das empresas mantenedoras. Os resultados da pesquisa de campo e dos testes de média não paramétricos indicam que houve redução nos custos de transação das empresas compradoras após a implantação do programa. Complementarmente, verificou-se que houve maior redução nos custos de transação relacionados às atividades posteriores (ex post) às transações de compra em comparação com os custos associados às atividades anteriores à transação de compra (ex ante).
\end{abstract}

Palavras-chave

Desenvolvimento de fornecedores. Instituições privadas. Custos de transação.

\section{Introdução}

Atualmente os fornecedores têm assumido um papel crítico para qualquer empresa. Ao prover materiais e serviços necessários à consecução das atividades fim da empresa foco, os fornecedores impactam diretamente nos custos e no desempenho da qualidade desta.

A redução de custos no processo de aquisição de bens e serviços tem sido uma das principais metas das empresas. Iniciativas como a adoção de sistemas de enterprise resource planning, fornecimento just in time, leilões reversos, global sourcing são exemplos de estratégias para redução de custos associados às atividades que não adicionam valor na cadeia de fornecimento (BHARADWAJA; MATSUNO, 2006).
Com fronteiras organizacionais mais fluidas, envolvendo redes de relacionamento, alianças estratégicas e parcerias entre fornecedores e compradores (VAN TULDER, 1999), estudos focados no entendimento do relacionamento comprador-fornecedor têm sido abundantes na literatura que trata da gestão de operações.

0 desenvolvimento de fornecedores, definido como qualquer esforço da firma compradora em aumentar o desempenho e as capacidades do fornecedor, tem se disseminado como prática estratégica (HUMPHREYS; $\mathrm{LI}$; CHAN, 2004). No entanto, os autores criticam a literatura sobre desenvolvimento de fornecedores por suas características excessivamente descritivas e focadas apenas nas práticas de desenvolvimento 
de fornecedores observadas nos Estados Unidos e nos países da Europa. Na mesma linha, Wouters, van Jarwaarde e Groen (2007) argumentam a favor da necessidade de entender estratégias e práticas de desenvolvimento de fornecedores locais, principalmente a partir de estudos de campo.

lttner et al. (1999) observaram que o desenvolvimento de parcerias entre fornecedores e compradores não necessariamente resulta na melhoria de desempenho dos últimos. Os resultados conseguidos pelos autores indicaram que, para obter benefícios de rentabilidade, qualidade do produto e relacionamento de longo prazo, é preciso que os compradores adotem procedimentos apropriados de seleção de fornecedores e monitoramento do seu desempenho.

Na mesma literatura observa-se ainda a necessidade de examinar empiricamente o impacto dos programas de desenvolvimento de fornecedores na eficiência da interface comprador-fornecedor (HUMPHREYS; Ll; CHAN, 2004).

0 presente estudo teve dois objetivos: o primeiro, entender como surgiu e se desenvolveu a instituição privada Programa Integrado de Desenvolvimento e Qualificação de Fornecedores (Prodfor), um programa específico de padronização e certificação de fornecedores locais de produtos e serviços no estado do Espírito Santo. 0 segundo objetivo foi testar se o programa de padronização e certificação de fornecimento causou redução de custos de transação para as mantenedoras nas compras de bens e serviços.

O Prodfor foi instituído em 1997, a partir da iniciativa de grandes compradoras, denominadas mantenedoras: Aracruz Celulose, Companhia Vale do Rio Doce, Petrobras, Companhia Siderúrgica de Tubarão, Grupo Arcelor, Energias do Brasil, Samarco, Belgo, Cesan, Chocolates Garoto, Canexus, Technip-Coflexip e Telemar. O Instituto Euvaldo Lodi (IEL) entrou e atua como parceiro certificador. 0 programa é integrado ao Sistema Confederação Nacional da Indústria (CNI), e regionalmente à Federação das Indústrias do Espírito Santo (Findes).

A proposição teórica que sustenta o estudo parte das literaturas de economia de custos de transação (WILLIAMSON, 1985; BARZEL, 2003) e de instituições privadas (AOKl, 2001; BROUSSEAU; RAYNAUD, 2006; GREIF, 2005), no racional de que programas de padronização e certificação são instituições privadas que atuam como fonte de enforcement com o objetivo de reduzir custos de transação das compradoras na aquisição de materiais e serviços.

0 presente estudo contribui para a literatura sobre desenvolvimento de fornecedores de duas maneiras. Primeiro, ao caracterizar o desenvolvimento do programa de certificação de fornecedores utilizando as proposições teóricas citadas, o presente estudo oferece uma lógica causal para explicar o processo de certificação observado. Segundo, a lógica causal desenvolvida permitiu a proposição de hipóteses teóricas empiricamente testáveis a respeito da redução de custos de transação nas compras das mantenedoras de um programa de certificação.

A pesquisa de campo incluiu duas etapas: uma qualitativa, envolvendo observação, entrevistas semiestruturadas e pesquisa documental; e uma etapa quantitativa, na qual foram aplicados questionários para levantar os dados a serem utilizados no teste estatístico das hipóteses teóricas. Os testes do impacto do Prodfor nos custos de transação ex ante e ex post das compradoras deu-se pela comparação destes custos com e sem a certificação, ou seja, entre as fases "antes" e "depois" do processo de certificação, visto como uma instituição, observando o método de análise econômica da dinâmica institucional proposto por Greif (1998)

\section{Estudos anteriores}

A provisão de serviços industriais envolve a decisão das indústrias entre produzir um serviço internamente ou comprar tal serviço de um fornecedor independente. 0 racional da economia dos custos de transação indica que a forma como a atividade é organizada importa, pois mesmo que os custos de produção dos bens e serviços sejam iguais, o custo de coordenação de cada forma alternativa de governança não é.

As firmas escolheriam entre realizar uma certa atividade internamente (e incorrer em custos da burocracia) ou utilizar um fornecedor externo (e incorrer em custos de transação) de forma a minimizar os custos de coordenar tal atividade (WILLIAMSON, 1985). Os custos de transação envolvem recursos empregados na seleção de fornecedores, na redação do acordo, na negociação, na resolução de conflitos e perdas decorrentes de falha de desempenho ou descumprimento do acordo. Williamson (1985) sugere que tais custos seriam função i) de quão específicos são os investimentos aplicados, ii) da frequência e iii) da incerteza envolvidas na transação. Sendo que um investimento é tão mais específico quanto mais os ativos empregados perderem valor se deixarem de ser empregados na atividade para a qual foram projetados.

Nesta perspectiva teórica, comprador e fornecedor não conseguem antecipar as contingências futuras da relação, tendo a relação de fornecimento coordenada por acordos (contratos) incompletos. As brechas contratuais levantam riscos contratuais 
que podem inibir investimentos especificos. Neste caso, compradores estariam dispostos a fazer tais investimentos específicos, treinando um fornecedor em particular ou desenvolvendo de forma compartilhada uma tecnologia de processo, caso tivessem uma razoável expectativa de que a relação duraria o suficiente para recuperar tais investimentos, ou que seriam de alguma forma compensados por um término antecipado.

Em Williamson (1996), as firmas teriam duas formas para reduzir tais riscos decorrentes de ativos específicos: i) alterando a forma de governança da atividade ou ii) alterando as características das atividades. No primeiro caso a firma terceiriza uma atividade ao ter expectativa de que os custos de transação serão menores em comparação aos custos de coordenar a atividade internamente. Neste caso, na presença de investimentos específicos o comprador optaria por relações de longo prazo (DYER, 1997; NOVAK; EPPINGER, 2001; VAN DER MEER-KOOISTRA; VOSSELMAN, 2006).

No segundo caso a firma alteraria a natureza da atividade, por exemplo, padronizando tal atividade, tornando-a menos específica. Nesta lógica, Barzel (2003) sugere que a padronização dos atributos de bens e serviços reduz os custos de transação, pois o comprador reduziria a especificidade dos ativos envolvidos na geração da atividade.

Por fim, tais transações acontecem imersas em um conjunto de instituições, "regras do jogo". Agentes privados podem criar e sustentar instituições privadas (BROUSSEAU; RAYNAUD, 2006; GREIF, 2005; AOKl, 2001), definindo regras de conduta e gerando enforcement, atuando como pano de fundo para formas de governança adotadas por tais agentes. A eficiência da instituição privada está associada ao grau com que os agentes são incentivados a cumprir a regra, dependendo de quão crivel é a ameaça da penalização e a perda associada, ou seja, o nível de enforcement (AOKl, 2001; GREIF, 2005).

Exemplo de tais instituições privadas são as regras implícitas nos programas de desenvolvimento, padronização e certificação de fornecedores. Enquanto a padronização seria uma forma de reduzir a especificidade dos ativos e, portanto, reduzir os custos de transação dos compradores, a certificação seria uma forma de enforcement para que fornecedores cumpram os padrões, sob a ameaça de serem excluídos do rol de fornecedores. Em outras palavras, a dinâmica da certificação seria explicada pela tentativa de minimização de custos de transação por parte dos compradores de maior porte, organizados em torno desse objetivo.

\subsection{Programas de desenvolvimento de fornecedores e desempenho}

Tanto para bens físicos quanto para serviços, a especificidade de ativos influencia a decisão de terceirizar e a escolha da forma de coordenar fornecedores externos.

Para melhoria de desempenho os compradores poderiam adotar estratégias que usam o mercado (arm's length) para promover a competição entre fornecedores, prometendo contratos futuros condicionados ao desempenho atual (KRAUSE, 1999, 1997; MODI; MABERT, 2007). Alternativamente, poderiam se envolver diretamente com um fornecedor e apoiar o desenvolvimento de seus processos. Neste caso os recursos empregados na relação, sejam investimentos de capital, orientação para melhorias de processos operacionais/ administrativos ou treinamento de pessoal técnico, são específicos àquele fornecedor (HEIDE; STUMP, 1995).

Compradores têm procurado a segunda estratégia, reduzindo o número de fornecedores, fazendo uso de relações de longo prazo e promovendo programas de desenvolvimento desses fornecedores, o que tem contribuído para melhorias em termos de qualidade, prazo e custo de produção (KRAUSE, 1997; WATTS; HAHN, 1993).

Evidências de estudos em organizações dos Estados Unidos e do Reino Unido (KRAUSE, 1997; WATTS; HAHN, 1993, HARTLEY; CHOI, 1996; MONCZKA; TRENT; CALLAHAN, 1993), e na Ásia (HUMPHREYS; LI; CHAN, 2004; WOUTERS; VAN JARWAARDE; GROEN, 2007), apontam que na presença de investimentos diretos em ativos específicos físicos ou humanos, dedicados a um fornecedor, o desempenho é melhorado quando são adotadas estratégias do segundo tipo, incluindo programas de desenvolvimento de fornecedores.

Os programas de desenvolvimento de fornecedores geralmente envolvem: a melhoria das metas de desempenho do fornecedor (MONCZKA; TRENT; CALLAHAN, 1993); treinamento para o fornecedor (GALT; DALE, 1991); apoio com equipamento, suporte tecnológico e investimentos (GALT; DALE, 1991; MONCZKA; TRENT; CALLAHAN, 1993); avaliação de desempenho do fornecedor (WATTS; HAHN, 1993) e o reconhecimento do desempenho através de recompensas e premiações (GALT; DALE, 1991).

Apesar da extensa literatura em adoção de programas de desenvolvimento de fornecedores, exceto estudos que tratam do que incentiva compradores a investirem nesses programas (KRAUSE, 1999), não foram encontrados estudos empíricos que discutem como surgem os programas de certificação, vistos como 
instituições privadas sustentadas por compradores, ou mesmo análises do impacto dos programas de certificação de fornecedores nos custos de transação dos compradores.

\section{Desenvolvimento das hipóteses}

\subsection{O impacto da padronização e da certificação na redução da incerteza e da especificidade de ativos}

No processo de aquisição de bens ou serviços, a seleção de fornecedores, a negociação, a redação do contrato ou pedido, as atividades de inspeção de qualidade e resolução de expectativas não atendidas representam custos da transação. Tais custos guardam relação com características das transações: a frequência com que a atividade é demandada pelo comprador; a incerteza envolvida na transação; e a especificidade dos recursos empregados para consecução da atividade de compra/fornecimento (WILLIAMSON, 1985).

Parte do total de custos de transação na aquisição de bens e serviços é incorrida ex ante à aquisição, tais como a seleção de fornecedores e a negociação. Outra parte desses custos é incorrida ex post à transação, tais como os esforços empregados na resolução de não conformidades.

Um produto ou serviço é caracterizado por um conjunto de atributos (BARZEL, 2003). 0 nível e a variabilidade do desempenho do produto ou serviço são peculiares ao fornecedor que o oferece. Para efeitos de planejamento e controle, é do interesse dos compradores estimar o desempenho do conjunto de atributos do bem a ser adquirido. Para isso, eles incorrem em custos de busca de informação sobre tais atributos.

Assumindo que sempre haverá assimetria de informação entre as partes que realizam a transação, sempre haverá também um risco associado à variabilidade do desempenho do bem adquirido (ROBERTSON; LANGLOIS, 1994). Assim, os fornecedores que conseguem reduzir a expectativa de variabilidade do desempenho dos seus produtos ou serviços têm, em relação aos fornecedores de maior risco ,maior probabilidade de serem contratados.

No entanto, atividades de fornecimento específicas demandam do fornecedor investimentos em ativos específicos, que perdem valor quando são deslocados de seu uso principal, o que pode resultar em barreiras de entrada que reduzem o número de fornecedores no mercado (WILLIAMSON, 1985). A padronização e a certificação representam esforços no sentido de reduzir tanto a incerteza como a especificidade dos ativos necessários ao fornecimento, aproximando a transação de uma condição de concorrência perfeita, com a consequente redução nos preços (BARZEL, 2003; BROUSSEAU; RAYNAUD, 2006).

A padronização é a convergência das escolhas individuais de compradores e fornecedores para um padrão existente ou proposto. Ao padronizar processos produtivos, definindo e documentando medidas, indicadores, atributos e formas de mensuração dos atributos envolvidos, é gerada, ex ante, uma interface comum a outros fornecedores e compradores (LANGLOIS, 1992). Ao fazer isso, aumenta-se a qualidade da informação sobre o desempenho de um produto ou serviço.

A certificação, que normalmente sucede a padronização, é a verificação do atendimento a um conjunto de regras explícitas, as quais incluem os mecanismos de coerção para o cumprimento do padrão (BARZEL, 2003). 0 grau de aplicação das regras privadas envolvidas na padronização e certificação é chamado enforcement, o qual depende da efetiva aplicação das punições em casos de descumprimento. Uma regra com baixo enforcement, ou seja, cujo não atendimento não gera perdas a quem a desconsidera parcial ou plenamente, deixa de ser seguida e com o tempo perde a credibilidade, mesmo que escrita e formalizada. Organizações de certificação surgem com objetivo de coordenar e implantar mecanismos de autorregulação e enforcement (MÉNARD, 2004). Tais organizações sinalizam aos compradores quais fornecedores têm maior propensão em cumprir os padrões de desempenho contratado.

Embora não tenha poder para condenar ao pagamento de indenização por danos causados ao outro contratante, a certificadora, com a informação sobre o histórico do certificado, tem como excluir o agente que não observar o padrão, envolvendo ostracismo pela "lista negra", ou a perda do "selo de certificado" (AOKl, 2001), impedindo-o de realizar novas transações num determinado grupo de clientes (AOKl, 2001; GREIF, 2005). Ao mesmo tempo, os não infratores têm incentivos para manter o "selo" de credibilidade, pelo potencial de transações futuras dentro do grupo de compradores.

A presença de certificação resulta em um efeito ainda maior na redução dos custos de transação, pois representa um mecanismo de enforcement. Aprofundando a análise da relação causal entre a certificação e os custos de transação, sugere-se que o impacto da certificação é moderado por duas outras variáveis, de acordo com as proposições de Brousseau e Raynaud (2006): i) a homogeneidade das necessidades específicas; e ii) a densidade das relações ou número de transações entre os compradores e potenciais fornecedores, conforme apresentado na Figura 1. 


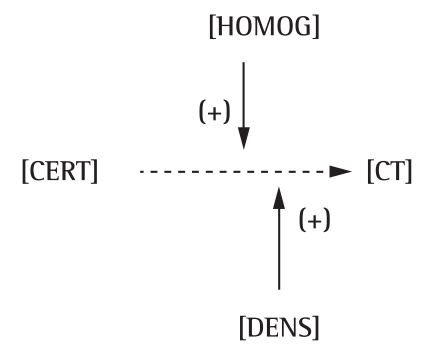

[HOMOG] Homogeneidade nas necessidades das compradoras

[DENS] Densidade das relações

[CERT] Padronização seguida de certificação

[CT] - Custos de transação (obtenção de informação, seleção, negociação, monitoramento, mal-adaptações e ajustes realizados)

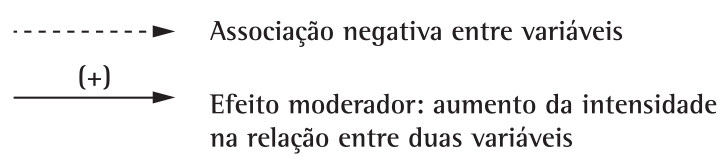

Figura 1. Impacto da certificação nos custos de transação das compras das mantenedoras. Fonte: elaborada pelos autores.

\subsection{Dinâmica da certificação}

No presente estudo, a relação causal apresentada na Figura 1 requer a análise em três etapas distintas do processo de certificação: i) fase anterior à criação do programa de certificação; ii) fase de criação do programa; e iii) fase de consolidação do programa.

A Figura 2 apresenta graficamente as três fases, nas quais o uso do potencial de fornecimento local $(q)$ em relação à demanda de uma atividade, em que $q \leq 1$, é função do nível de especificidade da atividade transacionada $(k)$. A frequência da atividade aqui será tratada como constante em relação à padronização e à certificação.

As áreas hachuradas representam "áreas de interesses comum”, ou seja, a zona em que as firmas compradoras e fornecedores transacionam, sendo que ocorrem transações entre $k_{a}$ 'e $k_{a}$.' Para qualquer transação com $k>k_{a}$ " não existe oferta por fornecedor local, pelo serviço altamente específico demandado. Cada compradora tem um grau mínimo de discricionariedade nos atributos dos bens demandados. Para qualquer $k<k_{a}$, não existe demanda, pois tais serviços são mais genéricos que as necessidades específicas de tais compradores, tais serviços alcançam assim uma alta padronização naturalmente. Por fim, na faixa $\left[k_{\mathrm{a}}, k_{\mathrm{a}}\right.$ '] a compradora aceita a incerteza condizente com a atividade, caso já tenha tomado a decisão de terceirização da atividade, e incorre em custos de proteção contratual, como inspeção de qualidade ou retrabalho. Os custos de transação decorrentes da falha de desempenho do fornecedor e da barganha na negociação limitam o uso do

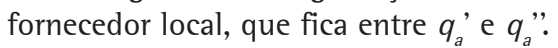

Com a convergência de interesses e início da implantação do programa, o cenário se altera de (a) para (b), e a faixa se amplia para direita $\left[q_{b}, q_{b}\right.$ ”] Contudo, pelo ainda baixo nível de participação o efeito da padronização não surge. Nessa faixa os custos de implantação não foram recuperados pela queda de custos de transação. 0 início do programa de certificação é uma fase de "aposta”, apesar dos aumentos da homogeneidade de interesses e da densidade das transações.

$\mathrm{Na}$ mudança de (b) para (c) o aumento dos fornecedores certificados potencializa a queda da especificidade das atividades e os níveis de incerteza, reduzindo custos contratuais e elevando o uso potencial do fornecimento local, portanto, ampliando e deslocando a faixa de fornecimento local para direita $\left[q_{c}^{\prime}, q_{c}^{\prime \prime}\right]$.

Abaixo de $k$ ', para quaisquer das fases, as compradoras não possuem atividades com tal especificação a serem demandadas, mantendo ainda um dado grau de discricionariedade nos produtos e serviços comprados. Atividades ofertadas altamente padronizadas perdem especialização e, portanto, podem deixar de atender determinadas necessidades. Assim, não é esperado que $q_{c}$ " se iguale a 1 .

\subsubsection{Fase anterior à criação do programa}

Anteriormente à criação do programa de certificação, os custos de transação das mantenedoras encontram-se num patamar superior pela alta especificidade de ativos e de atividades e alta incerteza, conforme representado na Figura 2a. Nessa fase, a padronização do fornecimento antes da certificação é menor que após a certificação, gerando incerteza entre o serviço contratado e o executado pelo fornecedor. A especificidade das encomendas enseja potencial de captura de renda (hold up) devido aos custos irrecuperáveis (sunk costs) arcados pelos fornecedores por investimentos já realizados. Ocorrem mal-adaptações e ajustes com trocas de fornecedores, acarretando custos irrecuperáveis na troca de fornecedores (switch costs) (WILLIAMSON, 1985), como custos de nova seleção e contratação, mensuração das etapas já realizadas e dificuldade de atribuição de responsabilidades por baixa qualidade que possam ser imputadas ao antigo ou ao novo fornecedor. 


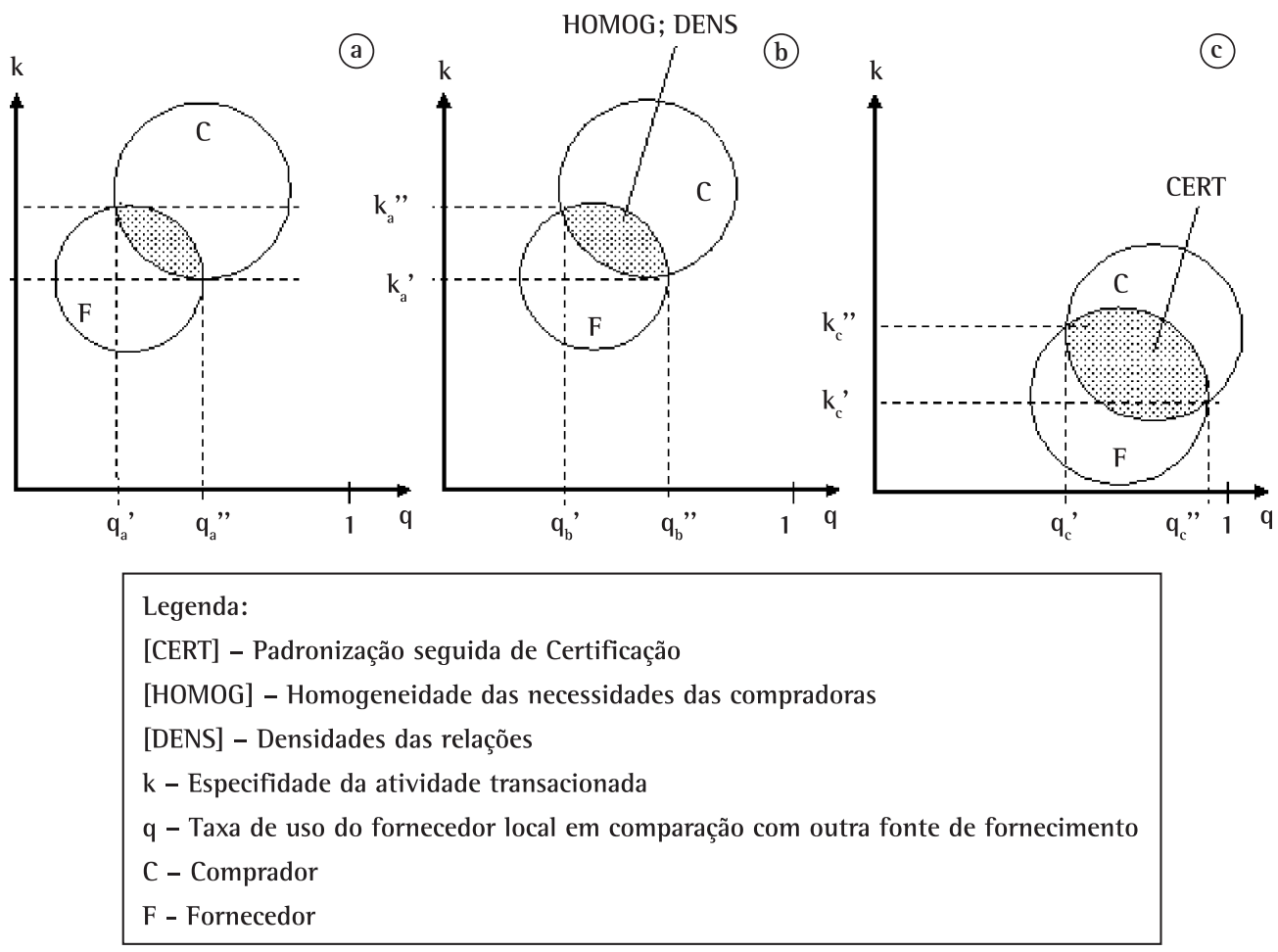

Figura 2. Fases do programa e impacto da especificidade de atividades e incerteza no uso do potencial de fornecimento local. Fonte: adaptada de Glachant, Dubois e Perez (2003) e Williamson (1991).

Nesta fase, espera-se que a captura de renda na transação por uma dada compradora de um dado fornecedor ocorra até o limite em que a expectativa de custos de transação, exemplificados pelos custos de seleção, negociação e contratação, inspeção e problemas de mal-adaptações, na execução do contrato com outro fornecedor não certificado sejam maiores que a parcela de renda capturada.

Seguindo o argumento desenvolvido, a firma compradora, isoladamente, arca com maiores custos de obtenção de informação para romper a assimetria informacional quanto à real capacidade do fornecedor. A primeira transação com novos fornecedores envolve custos com a coleta e manutenção de dados cadastrais, a busca de informações junto a outras áreas de compras, entre as mantenedoras, a verificação de credenciais, a experiência prévia e avaliação de desempenho do fornecedor, de forma individualizada em cada compradora.

Após a contratação, espera-se a incidência de custos elevados de monitoramento, falhas e impacto econômico destas e ajustes de contratos, os quais acarretam um baixo número de contratos com fornecedores locais, pela insuficiência de requisitos de capacidade, preço, qualidade e entrega. Antes do programa não existia entidade certificadora e cada compradora individualmente exercia seus esforços de seleção, informação e coerção.
A capacidade do fornecedor local percebida por uma compradora para uma dada transação pode ser maior, menor ou igual à real capacidade desse fornecedor em manter um dado nível de desempenho em relação à qualidade, custo e prazo. Esse conjunto de possibilidades está associado à maior incerteza quanto ao produto ou serviço a ser adquirido, decorrente dos custos de mensuração. Espera-se que na repetição da transação a área compradora aproxime sua percepção da capacidade à real capacidade do fornecedor.

\subsubsection{Fase de criação do programa}

A certificação estabelecida pelas compradoras, entidade certificadora e fornecedores torna-se possível pela convergência de interesses. Na Figura $2 \mathrm{~b}$ a "área de interesse comum" aumenta com a homogeneidade dos interesses, e subsequente convergência de interesses e mobilização de padrões transacionais. Tanto fornecedor quanto firma compradora desejam incrementar o uso potencial do fornecimento local.

Nesta fase as compradoras têm interesse em reduzir os níveis de especificidade dos atributos e de incerteza quanto à variabilidade desses atributos de qualidade, custo e prazo nas aquisições de produtos e serviços. Os fornecedores têm interesse de aproveitar oportunidades de fornecimento com as compradoras, 
a entidade certificadora tem interesse em desenvolver e promover a inclusão de fornecedores locais filiados à Findes, pois é alto o nivel de aquisições junto a fornecedores fora do Espírito Santo. Por um lado existe o interesse do governo local em manter divisas no estado, de outro lado as despesas com deslocamento de mão de obra dos fornecedores de outros estados, e custos logísticos em geral, repassados aos preços dos serviços, incentivam compradoras a preferir 0 mercado local.

\subsubsection{Fase de consolidação da autocertificação}

Após a criação do programa, um número crescente de fornecedores, 22 em 1998 a 241 em 2006, busca e obtém a padronização. Eles então são certificados, diminuindo a especificidade e a incerteza das transações de compra. A homogeneidade das demandas das compradoras e o aumento de transações envolvidas no grupo de fornecedores aderentes geram ganhos de escala nos procedimentos de padronização e certificação. 0 crescimento do programa se dá pela expectativa dos fornecedores em se certificarem, com vistas à manutenção do contrato ou à obtenção de novos contratos com uma ou várias mantenedoras.

A consolidação do programa dá-se de um lado pelo enforcement, constrangendo comportamentos e confiscando direitos, tais como a perda da certificação e de contratos. Por outro lado, consolida-se a certificação também como um conjunto ou sistema de representação sumária de crenças e valores compartilhados quanto à efetividade do enforcement de experiências anteriores, reduzindo custos de monitoramento e mal-adaptações (AOKl, 2001).

Nesta fase caem os custos de transação ex ante de cada compradora, pois a seleção, negociação, contratação de fornecedores locais certificados são facilitadas pela ampliada informação sobre fornecedores cadastrados, pelo estabelecimento de procedimentos padronizados que atendam as necessidades coletivas das compradoras e sinalizados pelo "selo" da certificação. Os custos com monitoramento e problemas de mensuração se reduzem sensivelmente, pela queda da especificidade das atividades.

Eleva-se a percepção, pelo comprador, da real capacidade do fornecedor, atestada por órgão independente, sem os elevados custos de informação ex ante particulares a cada mantenedora na fase anterior ao programa, que agora são rateados por um grupo em crescimento.

De acordo com as proposições de Aoki (2001), o enforcement coletivo privado da certificação reduz os custos de transação ex post de cada compradora. Custos de mensuração ex post e custos de capacitação de mão de obra são transferidos para o fornecedor na fase de padronização. A entidade certificadora, com o uso de auditorias, procura assegurar o cumprimento das regras. Problemas de mal-adaptações são minimizados pelo esforço e comprometimento do agente certificado, o que facilita ajustes para não perder o contrato, a certificação ou ser excluído de negociação com as compradoras.

Nesta fase diminui a dependência das compradoras de um pequeno número de fornecedores habituais que ocorria antes da certificação. Então, aumenta a probabilidade de queda do preço de aquisição de bens e serviços, pela competição entre os fornecedores certificados num determinado segmento. Aumenta também a probabilidade de produto ou serviço sem falha, reduzindo o potencial de seleção adversa. Os custos de agência ex ante são reduzidos nas fases de seleção e contratação.

Conforme o programa se consolida e aumenta o número de fornecedores locais certificados, diminui a importância do certificado como ganhador de pedido para o fornecedor local e cresce sua importância como um critério qualificador do fornecedor. A certificação passa a ser exigência mínima obrigatória para concretização de negócios (REVISTA..., 2006).

\subsection{Hipóteses}

Com base no exposto, sugere-se que, na decisão de compra, a área compradora seleciona o fornecedor pelo menor custo de transação em potencial para a transação em questão. Incrementalmente, a cada decisão procura reduzir os custos de transação totais da área, entre ex ante e ex post, e percebe na escolha de fornecedor certificado em detrimento do fornecedor não certificado uma forma de fazê-lo. Então:

- H1: A certificação de fornecedores locais reduz custos de transação ex ante.

- H2: A certificação de fornecedores locais reduz custos de transação ex post.

Ao aumentar a presença de fornecedores certificados, a compradora percebe redução nos custos ex ante e ex post. Tal redução de custos, transação a transação, compensa os custos de manutenção da entidade certificadora pela especialização da atividade e efeito escala, pois os custos de monitoramento da execução do contrato, ou ex post, são transferidos em grande parte à entidade certificadora (AOKl, 2001; BARZEL, 2003). 0 fornecedor arca com parte desses custos com as taxas de certificação. Outra parte desses custos recai sobre a compradora mantenedora, que rateia os custos restantes de implantar, manter, atualizar o programa e gerar enforcement coletivo privado, tais como auditorias e avaliações de desempenho de fornecedores. Como 
maiores esforços ex ante reduzem custos ex post, e parte dos custos ex post é repassada aos fornecedores, espera-se encontrar evidências de uma percepção de maior redução de custos ex post em comparação aos custos ex ante. Então:

- H3: A redução de custos ex post provocada pela certificação é maior que a redução de custos ex ante provocada pela mesma certificação.

\section{Aspectos metodológicos}

Com o objetivo de testar as proposições teóricas apresentadas na seção anterior, foi adotada uma estratégia de estudo de caso no Programa Integrado de Desenvolvimento e Qualificação de Fornecedores (Prodfor).

Foi identificado um total de 37 potenciais respondentes entre os responsáveis pelas áreas de compras e contratações das 12 mantenedoras e os representantes das mantenedoras no Comitê Executivo do Programa. Dos 37 questionários, 15 foram respondidos oriundos de nove mantenedoras. Dentre os não respondentes, parte se recusou a participar alegando questões de confidencialidade; parte envolveu compradores que foram remanejados para outras áreas da empresa e indicaram nomes dos respondentes corretos, mas estes não retornaram o contato.

Apesar dos dados terem sido coletados em uma parcela de mais de $50 \%$ da população, optou-se pela estratégia de estudo de caso pela sua característica de permitir análises holísticas e sensiveis ao contexto (PATTON, 2002). 0 objetivo foi aumentar a robustez do teste das proposições teóricas por meio da combinação de análises de dados qualitativos e quantitativos.

\subsection{Coleta de dados}

A coleta de dados foi realizada por meio de entrevistas semiestruturadas, pesquisa documental e aplicação de questionários. Os 19 informantes-chave foram selecionados segundo i) o papel dos mesmos na criação, representação e operacionalização do programa; e ii) no nível hierárquico de atuação do entrevistado na compradora (diretor executivo, gerentes de suprimentos ou de qualidade, auditores líderes etc.).

0 roteiro de entrevista procurou assegurar que as mesmas linhas básicas de investigação fossem exploradas com cada entrevistado (PATTON, 2002), adotando uma estratégia de conversação, de modo que $o$ entrevistador tivesse flexibilidade em decidir quando era apropriado se aprofundar em determinado tema ou apresentar questões que não tinham sido previamente planejadas (LEGARD; KEEGAN; WARD, 2003).
$\mathrm{Na}$ etapa de pesquisa documental, foram examinados documentos físicos e eletrônicos relacionados à certificação, como vídeos institucionais; Manual Sistema de Gestão da Qualidade em Fornecimento; relatórios de tratamento de produto não conforme; informativos e outras divulgações do Prodfor, assim como Registros da Análise Crítica da Qualidade.

0 questionário aplicado na etapa quantitativa considerou os tipos de custos de transação nas diversas fases do processo de compra, coerentes com a linha teórica (COASE, 1988; WILLIAMSON, 1985, 1991). Na sequência lógica para uma contratação, foram tomados os custos de: i) obter informação e seleção da contraparte; ii) negociação, decisão e contratação; iii) supervisão e inspeções para assegurar o cumprimento do contrato; e iv) mal-adaptações e ajustes contratuais.

Foi realizado teste piloto com 11 respondentes da área de compras, qualidade e área demandante das compradoras para buscar evidências de fontes de redução de custos de transação ex ante (seleção, negociação e contratação de fornecedores) e ex post (monitoramento e ajustes de contratos). As observações e dúvidas possibilitaram melhor contextualização da teoria e categorias e reformulação do questionário para que os respondentes efetivamente compreendessem as perguntas adequadas nas atividades de fornecimento.

\subsection{Análise dos dados}

Alguns cuidados recomendados (YIN, 2003; BARDIN, 1977; GROVES et al., 2004; McKINNON, 1988) foram tomados para reduzir as ameaças à validade das conclusões obtidas. Os dados qualitativos coletados foram codificados por aglutinação em categorias; buscou-se a convergência de pelo menos duas fontes de evidências, entre entrevistas semiestruturadas, documentos e questionários, e foi utilizado o processo de revisão por informantes-chave.

Optou-se pela apresentação da análise na forma da descrição do caso, construindo ao longo da descrição a triangulação de evidências de categorias (SCANDURA; WILLIAMS, 2000). 0 relatório do estudo de caso foi elaborado ao longo da pesquisa de campo, análise e classificação de dados e informações.

Para a análise de conteúdo das entrevistas e documentos foram definidas categorias, subcategorias e unidades de análise coerente com as etapas recomendadas por Groves et al. (2004) para a estratégia de estudo de caso. Tal procedimento visa reduzir o viés de percepção dos respondentes em entrevistas e a subjetividade do entrevistador. Raramente os estudos que envolvem custos de transação mensuram tais 
custos diretamente em termos monetários, dada a dificuldade de captá-los (SHELANSKI; KLEIN, 1995). Uma exceção pode ser vista em Masten, Meehan e Snyder (1991). Comumente são captadas as percepções sobre tais custos, trianguladas com outras fontes de evidências, o que permite alcançar melhores níveis de mensuração do construto.

0 programa, enquanto instituição privada, em seu aspecto dinâmico e estático, foi analisado por tópicos, em consonância com a teoria exposta, com enfoque nas categorias de análise definidas, a saber: i) mecanismos de geração da regra (design-enforcement) relacionados a custos de transação ex ante; e ii) mecanismos de coerção (coercion-enforcement) relacionados a custos de transação ex post.

Para mecanismos de geração da regra foram adotadas e verificadas as subcategorias de benefícios e limitações sugeridas pela teoria: a) negociação multilateral; b) especialização de regras e padronização de procedimentos em "pacote" que facilita a negociação e contratação, se enquadra nas necessidades específicas e é baseada no know-how das partes; c) economia de escala, escopo e aprendizagem na comunicação, informação e coordenação coletiva; d) renegociação baseada no aprendizado; e) mal-adaptações e potenciais dificuldades para criar instituições privadas; f) incompatibilidade com regras localizadas; e g) possibilidade de captura interna e externa (BARZEL, 2003; GREIF, 2005; AOK1, 2001; BROUSSEAU; RAYNAUD, 2006). Para custos de transação ex ante foram enumeradas as subcategorias custo de seleção, negociação e contratação (WILLIAMSON, 1991).

Para mecanismos de coerção foram adotadas e verificadas as subcategorias: a) economia de escala, escopo, aprendizagem e especialização; b) informação e retaliação coletiva (ostracismo); c) mecanismos que reduzem a não verificabilidade; d) legitimação por adesão voluntária e self-enforcing; e) decréscimo de eficiência pelo aumento do número de membros, tamanho e diversidade da comunidade; e f) possibilidade de saída (BARZEL, 2003; AOKI, 2001; GREIF, 2005; BROUSSEAU; RAYNAUD, 2006).
Para custos de transação ex post foram enumeradas as subcategorias custo de monitoramento e de mal-adaptações (WILLIAMSON, 1991).

$\mathrm{Na}$ etapa quantitativa, as hipóteses teóricas quanto à diferença de percepção sobre os custos antes e depois do programa foram testadas através de teste não paramétrico de Wilcoxon, por meio dos dados coletados pelo questionário. Utilizou-se o somatório das notas atribuídas por cada respondente, quanto aos custos antes e depois da certificação, tanto para os custos tipo ex ante quanto para os do tipo ex post ao contrato, para cada fase do processo de compras.

\section{Resultados e discussão}

Optou-se por apresentar os resultados do teste de hipóteses não paramétrico de Wilcoxon primeiramente. Em seguida, são apresentadas evidências qualitativas que conferem robustez aos resultados do teste. A Tabela 1 apresenta os resultados do teste de Wilcoxon.

Quanto aos custos ex ante, os resultados indicam a existência de diferença estatisticamente significativa entre as fases "antes" e "depois" da certificação para o fornecedor do programa. 0 valor-p encontrado $(0,001)$ permite rejeitar a hipótese nula de que a certificação não reduz ou aumenta os custos de transação ex ante para as compradoras. Sendo assim, sugere-se que a certificação promoveu redução de custos ex ante.

0 resultado converge com declarações de entrevistados: i) "o selo do programa dispensa prévia inspeção técnica em algumas contratações, dispensa maior coleta de informações externas para fornecedores não habituais" (entrevista no. 15); ii) "a certificação oferece maior segurança na contratação de serviços” (entrevista $n^{\circ}$. 13); iii) "a fornecedora certificada é mais organizada, mais ágil e mais precisa no cálculo do valor de sua proposta e na apresentação de propostas" (entrevista n ${ }^{0}$ 14); iv) "a qualificação agiliza a elaboração de repropostas, auxilia na precificação real do produto ou serviço sob encomenda que exigem qualidade técnica específica” (entrevista nº 11).

Tabela 1. Comparação entre a percepção dos custos de transação para os mantenedores do programa, segundo os responsáveis pelas áreas de compras.

\begin{tabular}{|c|c|c|c|c|}
\hline & \multicolumn{2}{|c|}{ Custos ex ante } & \multicolumn{2}{|c|}{ Custos ex post } \\
\hline & Antes** & Depois** & Antes** & Depois** \\
\hline Mínimo & 10,0 & 3,0 & 12,0 & 0,0 \\
\hline Máximo & 28,0 & 14,0 & 25,0 & 14,0 \\
\hline Média & 19,7 & 10,7 & 18,6 & 8,5 \\
\hline Mediana & 21,0 & 12,0 & 18,0 & 9,0 \\
\hline Desvio padrão & 5,3 & 4,0 & 3,5 & 4,2 \\
\hline Wilcoxon & \multicolumn{2}{|c|}{$-3,417$} & \multicolumn{2}{|c|}{$-3,310$} \\
\hline Valor-p & \multicolumn{2}{|c|}{$0,001^{*}$} & \multicolumn{2}{|c|}{$0,001^{*}$} \\
\hline
\end{tabular}

*Nivel de significância de 1\%. ${ }^{* *}$ Antes e depois do programa de certificação - Prodfor. Fonte: elaborada pelos autores. 
Da mesma forma, existem indícios de diferença nas fases "antes" e "depois" da certificação para os fornecedores do programa (valor- $p<0,05$ ), em relação aos custos ex post. 0 valor-p encontrado permite a rejeição da hipótese nula de que a certificação não reduz ou aumenta os custos de transação ex post para as compradoras. Ou seja, custos ex post também podem ter sido reduzidos pela certificação do programa.

Esse resultado coincide com o suporte teórico apresentado e converge com evidências qualitativas, como a afirmação obtida de que “[...] sem dúvida, é gritante a diferença entre o antes e o depois na organização, nos registros, na rastreabilidade do processo e até mesmo no caso de falhas o esforço e compromisso do fornecedor certificado em reparar ou minimizar o impacto da falha e corrigir o problema" (entrevista $\mathrm{n}^{\circ}$. 11). Um informante-chave declara que "a inspeção da compradora em itens críticos é indispensável, porém nos demais casos a compradora não precisa fazer marcação cerrada sobre um fornecedor após ser certificado" (entrevista $n^{0} .12$ ).

A coerção, conforme previsto na teoria, pode ter papel significativo nesses resultados. Conforme entrevista $n^{\circ}$. 14, o Sistema de Auditoria do Programa "[...] tem potencial para acarretar a perda do selo de certificação e a rescisão ou perda de contrato com uma das mantenedoras por não conformidade com os requisitos do programa. Isso exclui o fornecedor das oportunidades com todas as demais".

Os resultados, de forma geral, são coerentes também com o enunciado de que o programa "[...] minimiza custos, aumentando a confiança nos fornecedores, melhorando a qualidade e reduzindo os riscos de fornecimento inadequado. (INSTITUTO..., 2006, p. 15)”.

Por fim, indícios de coerção por ostracismo são evidenciados pela afirmação de entrevistado de que "o risco de perda de um contrato pode significar perder todas as demais oportunidades de contratos com as demais compradoras" (entrevista $n^{\circ}$. 14) e pela lista de fornecedores excluídos do programa, publicada a cada número da revista do programa.

Para o teste da hipótese $\mathrm{H}_{3}$, foi realizado o teste de Wilcoxon para verificar se a intensidade da redução de custos ex post provocada pela certificação é maior que a intensidade da redução de custos ex ante. 0 valor W encontrado $(202,0)$ é menor que o valor W crítico $(232,5)$, o que permite rejeitar a hipótese nula de que a redução de custos na etapa ex ante é igual ou maior que a redução de custos na etapa ex post. Ao nível de significância de 5\%, há indícios de que a redução de custos ex post é maior que a redução de custos ex ante, o que corrobora o conteúdo das entrevistas e também está de acordo com os pressupostos teóricos apresentados que relacionam padronização e certificação aos custos de transação (AOK1, 2001; BARZEL, 2003).

As evidências indicam que a implantação da certificação de fornecedores contribuiu para redução de custos nos processos de compras de bens e serviços. A coordenação coletiva e privada do arranjo multilateral da certificação é mais um instrumento para as mantenedoras, além do contrato e da lei, para assegurar enforcement do contrato com o fornecedor local.

Os resultados também indicam que o programa reduz riscos de fornecimento inadequado, de devolução de produtos e de horas ou dias parados para as mantenedoras. Observa-se uma associação entre padronização e certificação com redução de incertezas, de especificidade de ativos, os quais são fonte de custos para as compradoras. Tal associação estaria ainda vinculada ao aumento no número de transações com fornecedores locais.

Nota-se ainda que a capacitação e o monitoramento dos fornecedores mudaram de uma estrutura de custo individualizada por mantenedora para uma forma coletiva, resultando em benefícios de escala e escopo, especialização, aprendizagem e redução de custos com a implantação do programa.

As evidências qualitativas indicam que o nível de adesão e comprometimento das mantenedoras aos custos do enforcement coletivo, na forma de quantidade de auditores próprios por mantenedora, é variável e pode depender da homogeneidade das necessidades e da densidade ou número de transações, o que é coerente com as proposições teóricas sobre instituições privadas. As mal-adaptações causadas pela diversidade de setores econômicos, tamanho ou necessidades das compradoras podem se explicar porque algumas não adotam a certificação como diferencial durante a decisão de compras.

\section{Conclusão}

0 presente estudo teve dois objetivos complementares: primeiro, entender o surgimento e o desenvolvimento da instituição privada Programa Integrado de Desenvolvimento e Qualificação de Fornecedores (Prodfor), um programa específico de padronização e certificação de fornecedores locais de produtos e serviços no estado do Espírito Santo; e, segundo, avaliar se o programa de padronização e certificação de fornecimento causou redução de custos de transação para as mantenedoras nas compras de bens e serviços. 
Os resultados da etapa quantitativa da pesquisa permitem concluir que houve redução nos custos de transação das empresas compradoras após a implantação do Prodfor. Os resultados da etapa qualitativa reforçam a confiança na causalidade proposta. Adicionalmente, é possível concluir que a abordagem econômica institucional para explicar as instituições privadas se aplica consistentemente no caso do Prodfor, pois os resultados da etapa qualitativa dão suporte empírico à dinâmica construída a partir das deduções teóricas.

Quanto às limitações do estudo, o número de questionários impediu o teste da redução de custos de forma segregada, e em grupos de respondentes de segmentos econômicos similares, como indústrias de base na área de mineração, siderurgia, metalurgia, e as demais, as quais incluem serviços públicos, alimentos e química. Dessa forma, não permitiu a análise de certos controles, como as diferenças no estilo e intensidade de negociação, e o nível de qualidade técnica e impacto da falha de fornecimento da atividade desenvolvida. A não divulgação da série histórica da quantidade e valor de contratos entre cada mantenedora transacionados com cada fornecedor restringiu a análise do efeito densidade de relações. Ainda, a simplificação do modelo testado não permitiu discutir os impactos da transferência de tecnologia durante o processo, o que pode justificar os diferentes ganhos por segmento de atividade.

A expansão dos resultados particulares dessa pesquisa poderia vir da investigação do outro lado da relação. Controlando a natureza e a frequência das atividades, estudos posteriores podem abordar o comportamento dos fornecedores frente à padronização e certificação compulsórias, representando perda de diferenciação e maior pressão de preços.

Por fim, dado que uma das possibilidades de verificação da explicação do estudo de campo é a replicação em outros eventos similares, a validação do resultado desse estudo pode ser beneficiada por contextos fáticos semelhantes ao que favoreceram o Prodfor: i) grandes compradores aglutinados numa pequena área geográfica; ii) necessidades homogêneas de fornecimento desses compradores; iii) adensamento de fornecedores já com relativo grau de desenvolvimento instalados nas proximidades das compradoras e mantenedoras; iv) reputação da entidade certificadora e experiência anterior positiva no fortalecimento de parceria com fornecedores. Nesse sentido, destaca-se que o arranjo coletivo do programa possibilitou a emergência de arranjos semelhantes em outros estados, como Maranhão, Pará, Goiás e Bahia.

\section{Referências}

AOKl, M. Toward a Comparative Institutional Analysis. The MIT Press, 2001.

BARDIN, L. Análise de conteúdo. Lisboa: Edições 70, 1977.

BARZEL, Y. Standards and the form of agreement. Budapeste: International Society for Institutional Economics - ISNIE, 2003.

BHARADWAJA, N.; MATSUNO, K. Investigating the antecedents and outcomes of customer firm transaction cost savings in a supply chain relationship. Journal of Business Research, v. 59, n. 1, p. 62-72, 2006. http:// dx.doi.org/10.1016/j.jbusres.2005.03.007

BROUSSEAU, E.; RAYNAUD, E. The economics of private institutions: An Introduction to the Dynamics of Institutional Frameworks and to the Analysis of Multilevel Multi-Type Governance. Colorado: International Society for Institutional Economics-ISNIE, 2006.

COASE, R. H. The nature of the firm. 1937. In: The Firm, the Market and the Law. The University of Chicago Press, 1988.

DYER, J. H. Effective interfirm collaboration: how firms minimize transaction costs and maximize transactional value. Strategic Management Journal, v. 18, n. 7, p. 535-556, 1997. http://dx.doi.org/10.1002/(SICI) 109 7-0266(199708) 18:7\%3C535::AID-SMJ885\%3E3.0.C0; $2-\mathrm{Z}$

GALT, J. D. A.; DALE, B. G. Supplier development, a British case study.International Journal of Purchasing and Materials Management, v. 27, n. 1, p. 16-22, 1991.

GLACHANT, J. M.; DUBOIS, U.; PEREZ, Y. Deregulating with no regulation: ls Germany electricity transmission regime institutionally correct? Budapeste: International Society for Institutional Economics - ISNIE, 2003.

GREIF, A. Commitment, Coercion, and Markets: The Nature and Dynamics of Institutions Supporting Exchange. In: MÉNARD, C.; SHIRLEY, M. M. (Eds.). Handbook of New Institutional Economics. New York: Springer, 2005. http://dx.doi.org/10.1007/0-387-25092-1_29

GREIF, A. Historical and Comparative Institutional Analysis. American Economic Review, v. 88, n. 2, p. 80-84, 1998.

GROVES, R. M. et al. Survey Methodology. New Jersey: John Wiley \& Sons, 2004.

HARTLEY, J. F.; CHOI, T. Y. Supplier development: customers as a catalyst of process change. Business Horizons, v. 39, n. 4, p. 37-44, 1996. http://dx.doi.org/10.1016/ S0007-6813(96)90050-6

HEIDE, J. B.; STUMP, R. L. Performance implications of buyer-supplier relationships in industrial markets: a transaction cost explanation. Journal of Business Research, v. 32, p. 57-66, 1995. http://dx.doi. org/10.1016/0148-2963(94)00010-C

HUMPHREYS, P. K.; Ll, W. L.; CHAN, L.Y.The impact of supplier development on buyer-supplier performance. Omega, v. 32, n. 1, p. 131-143, 2004. http://dx.doi. org/10.1016/j.omega.2003.09.016

INSTITUTO EUVALDO LODI - IEL. 200 MAIORES empresas do Espírito Santo. Revista Findes/IEL/IDEIES, 2006.

ITTNER, C. D. et al. Supplier selection, monitoring practices, and firm performance. Journal of Accounting and Public Policy, v. 18, n. 1, p. 253-281, 1999. http://dx.doi. org/10.1016/S0278-4254(99)00003-4 
KRAUSE, D. R. Supplier development: current practices and outcomes. International Journal of Purchasing and Materials Management, v. 33, n. 2, p. 12-9, 1997.

KRAUSE, D. R. The antecedents of buying firms' efforts to improve suppliers. Journal of Operations Management, v. 17, n. 2, p. 205-24, 1999. http://dx.doi.org/10.1016/ S0272-6963(98)00038-2

LANGLOIS, R. N. Transaction-cost economics in real time. Industrial and Corporate Change, v. 1, n. 1, 1992. http:// dx.doi.org/10.1093/icc/1.1.99

LEGARD, R.; KEEGAN, J.; WARD, K. In-depth interviews. In: RITCHIE, J.; LEWIS, J. (Eds.). Qualitative research practice: A guide for social research students and researchers. Thousand Oaks: Sage, 2003. p. 138-169.

MASTEN, S. E.; MEEHAN, J.; SNYDER, E. The costs of organization.Journal of Law, Economics and Organization, v. 7, p. 256-280, 1991.

McKINNON, J. Reliability and validity in field research: some strategies and tactics. Accounting, Auditing \& Accountability Journal, v. 1, n. 1, p. 34-54, 1988. http:// dx.doi.org/10.1108/EUM0000000004619

MÉNARD, C. The economics of hybrid organizations. Journal of Institutional and Theoretical Economics, v. 160, n. 3, p. 345-376, 2004. http://dx.doi. org/10.1628/0932456041960605

MODI, S. B.; MABERT, V. A. Supplier development: Improving supplier performance through knowledge transfer. Journal of Operations Management, v. 25, n. 1, p. 42-64, 2007. http://dx.doi.org/10.1016/j.jom.2006.02.001

MONCZKA, R. M.; TRENT, J. T.; CALLAHAN, T. J. Supply base strategies to maximize supplier performance. International Journal of Physical Distribution \& Logistic Management, v. 23, n. 4, p. 42-54, 1993. http://dx.doi. org/10.1108/09600039310041509

NOVAK, S.; EPPINGER, S. D. Sourcing by design: product complexity and the supply chain. Management Science, v. 47, n. 1, p. 189-204, 2001. http://dx.doi.org/10.1287/ mnsc.47.1.189.10662

PATTON, M. Q. Qualitative Research and Evaluation Methods. 3. ed. Thousand Oaks: Sage Publications, 2002.
REVISTA DO PRODFOR. Edição de Lançamento, Edições n. 1-19, 2002-2006.

ROBERTSON, P. L.; LANGLOIS, R. N. Innovation, networks, and vertical integration. University College and University of Connecticut, 1994.

SCANDURA, T. A.; WILLIAMS, E. A. Research Methodology in Management: Current Practices, Trends, and Implications for Future Research. The Academy of Management Journal, v. 43, n. 6, p. 1248-1264, 2000. http://dx.doi. org/10.2307/1556348

SHELANSKI, H. A.; KLEIN, P. G. Empirical Research in Transaction Cost Economics: A Review and Assessment. Journal of Law, Economics, \& Organization, v. 11, n. 2, p. 335-361, 1995.

VAN TULDER, R. Redrawing Organizational Boundaries. Sviib/Department of Public Management, Rotterdam School of Management, Erasmus University, Rotterdam, 1999. p.1-37.

VAN DER MEER-KOOISTRA, J., VOSSELMAN, E. G. J. Research on management control of interfirm transactional relationships: whence and whither. Management Accounting Research, v. 17, p. 227-237, 2006. http:// dx.doi.org/10.1016/j.mar.2006.06.003

WATTS, C. A.; HAHN, C. K. Supplier development program: an empirical analysis. International Journal of Purchasing and Materials Management, v. 29, n. 2, p. 11-7, 1993.

WILLIAMSON, O. E. Comparative Economic Organization: The Analysis of Discrete Structural Alternatives. Administrative Science Quarterly, v. 36, n. 2, p. 269-296, 1991.

WILLIAMSON, O. E.The Economic Institutions of Capitalism: Firms, Markets, Relational contracting. New York: Free Press, 1985.

WILLIAMSON, 0. E. The Mechanisms of Governance. New York: Oxford University Press, 1996.

WOUTERS, M.; VAN JARWAARDE, E.; GROEN, B. Supplier development and cost management in Southeast Asia: Results from a field study. Journal of Purchasing \& Supply Management, v. 13, n. 1, p. 228-244, 2007. http://dx.doi.org/10.1016/j.pursup.2007.07.002

YIN, R. K. Estudo de caso: planejamento e métodos. São Paulo: Bookman, 2003.

\title{
Supplier certification and transaction costs: effects of the prodfor - integrated program for development and qualification of supplier
}

\begin{abstract}
This research had two main purposes: understanding the development of the private institution "Programa Integrado de Desenvolvimento e Qualificação de Fornecedores - (PRODFOR)”, a program directed to the standardization and certification of local suppliers in the State of Espirito Santo; and testing hypotheses related to the program's impact on the transaction costs of the buyer companies. The concepts from the New Institutional Economics were used in order to develop hypotheses regarding the impact of certification on the sponsors' buying performance. The results obtained from the field research and the non-parametric tests of equality of means revealed that the certification caused a reduction on both the ex-ante and the ex-post buyers' transaction costs. Moreover, it was possible to observe that the impact was greater on the ex-post transaction costs.
\end{abstract}

\section{Keywords}

Suppliers development. Private institutions. Transaction costs. 